Artículo

\title{
Actividad antimicrobiana de extractos de Zingiber officinale y Maclura pomifera sobre Pseudomona syringae
}

\author{
Erika Natalia Ríos-Herrera ${ }^{1}$ \\ Alberto Margarito García-Munguía ${ }^{1 \S}$ \\ Omegar Hernández-Bautista ${ }^{2}$ \\ Carlos Alberto García-Munguía ${ }^{3}$ \\ ${ }^{1}$ Departamento de Ciencias Agronómicas-Centro de Ciencias Agropecuarias-Universidad Autónoma de \\ Aguascalientes. Aguascalientes, México. CP. 20100. (riosherreranataliae@gmail.com). ${ }^{2}$ CULTA SA de \\ CV. El Mante, Tamaulipas, México. CP. 89880. (omegarhbautista@gmail.com). ${ }^{3}$ Departamento de \\ Veterinaria y Zootecnia-División de Ciencias de la Vida-Universidad de Guanajuato. \\ (cagamu@ hotmail.com). \\ ${ }^{\S}$ Autor para la correspondencia: almagamu@ @otmail.com.
}

\section{Resumen}

El frijol y el tomate en México son dos de los productos que forman parte esencial de la dieta de la población de este país, es de gran importancia económica, cultural y gastronómica. La presencia de plagas y enfermedades en los cultivos aumenta los costos de producción, además del impacto ambiental y la residualidad de los plaguicidas pueden afectar la salud humana. El objetivo principal de la investigación fue estudiar una alternativa de biocontrol para enfermedades bacterianas, efectiva, de bajo costo y menor impacto ambiental. Se desarrolló en la ciudad de Aguascalientes, México en el año 2019. Fueron producidos extractos naturales (etanol, metanol y agua) de Maclura pomifera y Zingiber officinale en forma cruda por medio de maceración y concentrados por vía de rotaevaporación, utilizando bases de etanol, metanol y agua. Se aislaron e identificaron cepas de Pseudomona syringae de patologías en tomate y ejote. Se utilizaron 14 tratamientos con tres repeticiones de extractos crudos y concentrados. La actividad bactericida fue evaluada por medio de antibiogramas con intervalos de $24 \mathrm{~h}$ por siete días. Mostrando el mayor efecto inhibitorio, los extractos de $M$. pomifera base etanol de $100 \mathrm{mg} \mathrm{ml}^{-1}$ y Z. officinale de $100 \mathrm{mg} \mathrm{ml}^{-1}$ base etanol. Para el segundo ensayo en la disminución de concentraciones, se reiteró la efectividad de los extractos de $M$. pomifera en bajas concentraciones, siendo $10 \mathrm{mg} \mathrm{ml}^{-1}$ la concentración más baja y efectiva en la inhibición bacteriana. Lo anterior, posiciona a los extractos vegetales de $M$. pomifera como una opción, viable, eficaz y económica en el biocontrol de enfermedades bacterianas agrícolas.

Palabras clave: Maclura pomifera, Pseudomona syringae, Zingiber officinale, biocontrol.

Recibido: enero de 2021

Aceptado: febrero de 2021 


\section{Introducción}

En México el frijol y el tomate forman una parte importante de la alimentación básica de la población. Por su parte la producción de frijol en nuestro país destaca debido a la superficie sembrada y por ser el quinto país en producción de leguminosas a nivel mundial con 5.8\%, por debajo de Brasil con $16 \%$ de la producción total, India15.9\%, Myanmar $10.5 \%$ y China $8.9 \%$ (Lépiz et al., 2015; Lépiz et al., 2016). México ocupa el segundo lugar por superficie cosechada e frijol, después del maíz (Lépiz et al., 2015; Lépiz et al., 2016; SIAP, 2019).

La superficie total cosechada en tomate rojo registró un aumento de $2.8 \%$ para el ciclo 2019 con 21246 ha, en comparación a 2018 con 20659 ha. Registrando una producción acumulada a noviembre de 2019 de 52646 t, para este caso a diferencia del frijol, la producción se incrementó 822 t en relación con la obtenida en el mismo periodo del año anterior (1 524826 t), siendo Baja California (30 768 t), Durango (17 765 t), Aguascalientes (9 815 t) y Zacatecas (9 126 t), las entidades con mayores aumentos en producción del último año, con respecto al 2018 (SIAP, 2019).

A nivel mundial la producción de cultivos agrícolas se ve limitada o disminuida principalmente por patógenos causantes de enfermedades las cuales son combatidas tradicionalmente por métodos químicos que además de presentar residualidad y toxicidad en el ambiente, afectan la salud humana, mientras que la generación de resistencia de los agentes patógenos es una consecuencia común del uso excesivo de estos. Dicha resistencia provoca el aumento en la dosificación y por lo tanto el alza gradual en los costos de producción de alimentos (Reyes et al., 2015; Cúndom et al., 2016).

Se tiene una proyección para el año 2030 del doble del consumo actual de productos químicos. El uso prolongado de antimicrobianos en el control de enfermedades de animales y plantas puede provocar resistencia bacteriana. Por lo cual el adecuado, eficaz y controlado uso de estos, ayudará a mantenerlos efectivos, moderando su prevalencia en campo (FAO, 2017).

Preocupados tanto por el cuidado del planeta, la toxicidad, residualidad y costos de producción, hoy en día se investigan nuevas alternativas en el manejo de enfermedades en cultivos, dando paso al control biológico, el cual implica el uso de organismos vivos capaces de combatir a los fitopatógenos, así como metabolitos de estos o de algunas plantas que ayuden al control de enfermedades mediante la producción de compuestos bioactivos (Reyes et al., 2015; Solís y Armas, 2017; Pérez et al., 2018).

En los últimos años, ha ido en aumento el uso de recursos naturales y sus productos o subproductos. Esto podría ser debido a las publicaciones de nuevos conocimientos sobre su composición química y a la realización de diversos ensayos que sustentan su efectividad (Abadie et al., 2014; Pérez et $a l ., 2017)$. Entre sus principales efectos se le atribuyen: actividad antibacteriana, antifúngica, antiviral, antioxidante, anticancerígenas, entre otras. Por lo que las investigaciones se han enfocado en el estudio y búsqueda de nuevas sustancias de origen vegetal, que comprueben su efectividad ante los patógenos y puedan ser la nueva fuente de antibacterianos (Rojas et al., 2016).

En apoyo a esta iniciativa mundial, el presente trabajo se enfoca en la investigación de nuevas alternativas con el uso de productos vegetales, como lo son los extractos de plantas, para el control de enfermedades bacterianas causadas por Pseudomona syringae en hortalizas de importancia económica en México y el mundo como lo son el tomate y el frijol. 


\section{Materiales y métodos}

\section{Ubicación experimental}

El trabajo experimental se desarrolló en el periodo de 2019, en el laboratorio de Parasitología Agrícola del Centro de Ciencias Agropecuarias, de la Universidad Autónoma de Aguascalientes, donde se realizaron las pruebas in vitro y aislamiento de los fitopatógenos.

\section{Obtención de extractos vegetales}

En la ciudad de Parras de la fuente, Coahuila, con las coordenadas 25.4949609, -102.1836501, fueron colectados frutos de Maclura pomifera y transportados en rejas de madera a la ciudad de Aguascalientes. Los frutos fueron desinfectados utilizando hipoclorito de sodio al 3\%, cortándolos en trozos entre dos y tres centímetros, dejándolos secar en charolas con papel absorbente a $35^{\circ} \mathrm{C}$ de cinco a siete días, hasta que los frutos perdieron la humedad. Las raíces de jengibre obtenidas locales comerciales en la ciudad de Aguascalientes (Zingiber officinale) fueron tratadas de la misma forma, fraccionadas y secadas en las condiciones descritas para los frutos de Maclura pomifera.

Los materiales secos se pulverizaron utilizando un molino electromecánico marca COSUAI, número de modelo: CS-700. El material pulverizado fue almacenado hasta su maceración. Utilizando etanol, metanol y agua como vehículos de extracción, la maceración se llevó acabo a temperatura ambiente, en agitación constante sobre parrilla magneto mecánica, durante $72 \mathrm{~h}$ a una proporción de $70 \mathrm{~g} \mathrm{~L}^{-1}$ del solvente de extracción.

Utilizando papel filtro Whatman grado 1:11 $\mu \mathrm{m}$ se filtró el producto de la maceración separando la fase acuosa en dos partes de igual volumen. La primera parte fue almacenada a $4{ }^{\circ} \mathrm{C}$ en ausencia de luz, la segunda parte de los extractos alcohólicos se procesó en rotavapor Büchii B $490^{\circledR}$ a 58 ${ }^{\circ} \mathrm{C}, 75 \mathrm{rpm}$ y 35 psi. Llevando a sequedad total los últimos $10 \mathrm{ml}$ sobre caja Petri de vidrio abierta en estufa Felisa modelo FE-131 a $39^{\circ} \mathrm{C}$, secando de igual forma los extractos acuosos hasta obtener una capa seca o gomosa perdiendo la totalidad del solvente. Los extractos secos fueron identificados y almacenados a $4{ }^{\circ} \mathrm{C}$ en ausencia de luz.

\section{Concentraciones establecidas para los tratamientos}

La concentración establecida para cada tratamiento fue calculada en miligramos por mililitro. Se establecieron un total de 14 tratamientos. Tres tratamientos con extractos crudos de etanol, metanol y agua, sumado a esto, tres concentraciones diferentes para cada uno de estos extractos, utilizando en un primer ensayo, 500, 300 y $100 \mathrm{mg} \mathrm{ml}$ por cada extracto mencionado, para un total de nueve tratamientos más, un testigo absoluto (en proporción 1:1:1 agua destilada estéril, etanol y metanol) $\mathrm{y}$ un testigo comercial utilizando un producto liberado de acuerdo a las indicaciones y concentración recomendada por el fabricante, producto a base de tres extractos vegetales (Gamma de Progranic: extracto de ajo (Allium sativum 25\%), extracto de chile picante (Capsicum frutescens $25 \%$ ), extracto de canela (Cinnamomum zeylanicum 10\%) de 1.5-2 $\mathrm{L} \mathrm{ha}^{-1}$ en $200 \mathrm{~L}$ de agua). 
Estableciendo un segundo bioensayo con una reducción de concentraciones para los extractos de Maclura pomifera evaluando 14 tratamientos totales en la distribución anterior con la variación de

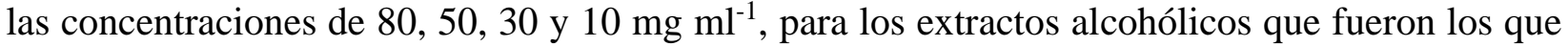
presentaron un mejor resultado en la primera etapa experimental.

\section{Aislamiento e identificación preliminar de cepas bacterianas}

Pseudomona syringae fue aislada de vainas de ejote con los síntomas de manchas grasientas, mientras que en tomate se seleccionaron frutos con pecas pequeñas de color negro, de 1 a $3 \mathrm{~mm}$ de diámetro, signos característicos de las enfermedades bacterianas respectivas para cada cultivo. Tanto los ejotes como el tomate fueron colectados de cultivos comerciales de la ciudad de Aguascalientes.

El aislamiento se realizó el laboratorio de Parasitología Agrícola de la Universidad Autónoma de Aguascalientes de acuerdo, a la metodología descrita por Agrios (2005): Zhang et al. (2017); P. syringae fue purificado por la técnica estría por cuadrantes, realizando pruebas preliminares como tinción de gram, oxidasa, prueba de ryu, catalasa y fluorescencia en medio B de king, corroborando su identidad molecular por medio de la secuenciación del material genético extraído de cultivos puros.

\section{Identidad molecular de bacterias fitopatógenas por gen 16S rDNA}

El DNA genómico de las cepas presuntivas de $P$. syringae, caracterizadas inicialmente por pruebas preliminares y Gram, fueron procesadas partiendo de aislados en tubos de caldo LB (Luria Bertani LB marca Dibico ${ }^{\circledR}$, cloruro de sodio 5, extracto de levadura 5, peptona de caseína $10(\mathrm{pH} 7.2 \pm 0.2)$ incubado a $26^{\circ} \mathrm{C}$ durante $48 \mathrm{~h}$ en agitador rotativo, realizando el aislamiento del material genético de acuerdo, a los métodos descritos por Ríos et al. (2016). Utilizando este como molde en el proceso de amplificación en las reacciones de PCR (Polymerase Chain Reaction), se prepararon reacciones de $20 \mu 1$.

La amplificación del gen de ADNr $16 \mathrm{~S}-23 \mathrm{~S}$ se llevó a cabo por los cebadores F1624 (3'CCTTTGTACACACCGCCCGTCG-5') y R1494 (5'-CTACGGRTACCTTGTTACGAC-3'). Cada mezcla de reacción $(20 \mu \mathrm{l})$ contenía $0.2 \mu \mathrm{l}$ de Taq DNA polimerasa $\left(1 \mathrm{U} \mu \mathrm{l}^{-1}\right), 2 \mu \mathrm{l}$ de $10 \mathrm{x}$ PCR Buffer QIA, $0.5 \mu \mathrm{l}$ de DMSO, $0.4 \mu \mathrm{l}$ dNTPs $\left(10 \mathrm{mmol} \mathrm{L}^{-1}\right), 0.8 \mu \mathrm{l}\left(5 \mu \mathrm{mol} \mathrm{L} \mathrm{L}^{-1}\right)$ de cada cebador, $14.3 \mu \mathrm{l}$ de agua Milli-Q y $1 \mu \mathrm{l}$ de ADN molde a $20 \mathrm{ng}^{-1} \mathrm{l}^{-1}$. Utilizando un termociclador de DNA Bio-Rad T100 ${ }^{\circledR}$, se estableció un programa de desnaturalización a $95^{\circ} \mathrm{C}$ durante 2 min, seguido de 35 ciclos de temperatura de $95{ }^{\circ} \mathrm{C}$ durante $40 \mathrm{~s}, 55^{\circ} \mathrm{C}$ durante $30 \mathrm{~s}$ y $72{ }^{\circ} \mathrm{C}$ durante 1 min y $30 \mathrm{~s}$, terminando con una extensión a $72{ }^{\circ} \mathrm{C}$ durante $7 \mathrm{~min}$. La amplificación se observó en gel de agarosa al $1 \%$ mediante electroforesis a $60 \mathrm{~V}$. Los productos de PCR se aumentaron y purificaron usando un kit de purificación de PCR GeneAll ${ }^{\circledR}$ ExpinTM SV.

La secuenciación de las regiones parciales 16S rDNA fue realizada por el laboratorio Macrogen (Rockville Maryland, EE. UU.). Las secuencias obtenidas fueron editadas manualmente eliminando los extremos con omisiones de bases, para aumentar la sensibilidad del análisis, estas secuencias purificadas, se analizaron en la base de datos del National Center for Biotechnology Information (NCBI)-GenBank. 


\section{Actividad antimicrobiana de los extractos vegetales}

Utilizando el protocolo de antibiograma, las cepas axénicas identificadas de los síntomas característicos de la enfermedad se inocularon dos tubos de caldo de soya Tripticaseína BD Bioxon ${ }^{\circledR}$ transfiriendo con asa bacteriológica una colonia con crecimiento de $24 \mathrm{~h}$ en caja de Petri, incubandose por $8 \mathrm{~h}$ a $28{ }^{\circ} \mathrm{C}$. En condiciones asépticas bajo campana de flujo laminar Eseve ${ }^{\circledR}$ modelo CFL102, agitando el tubo con crecimiento bacteriano se introduce el hisopo estéril y se quita el exceso de caldo presionando contra las paredes del tubo. Sobre placas de Petri con agar Mueller Hilton, se extiende una capa del caldo bacteriano con ayuda del hisopo a lo largo y ancho de la placa dejando secar por un minuto. Discos de $6 \mathrm{~mm}$ de papel filtro Whatman grado 1:11 $\mu \mathrm{m}$ se perforaron y esterilizaron para ser impregnados por los extractos a distintas concentraciones, estos fueron colocados en cuatro puntos distantes entre sí y uno al centro por cada unidad experimental. Las placas de Petri se identificaron e incubaron a $28{ }^{\circ} \mathrm{C}$ durante $24 \mathrm{~h}$.

La actividad antimicrobiana fue determinada cada $24 \mathrm{~h}$ por siete días, midiendo los halos de inhibición producidos por contacto y por las sustancias activas en los discos, utilizando una regla de plástico graduada en mm. Los resultados registrados cada $24 \mathrm{~h}$ sobre los halos producidos $\mathrm{y}$ medidos en $\mathrm{cm}$, fueron analizados por el programa estadístico R versión 3.6.3 (R Core Team, 2020). Los datos se analizaron bajo un diseño factorial y agrupación de medias, con 14 tratamientos, tres repeticiones por tratamiento, y cinco unidades de medida por unidad experimental (número de discos por caja).

\section{Resultados y discusión}

\section{Obtención de extractos vegetales}

Los extractos macerados y obtenidos de las raíces de jengibre (Zingiber officinale) y los frutos de Maclura pomifera en forma cruda tuvieron una recuperación de 96 y 95\%. Mientras que por rotaevaporación la concentración de extractos puros concentrados redujeron su rendimiento hasta un $2.7 \%$ y $3.4 \%$ p/p respectivamente de acuerdo, a su relación de peso y el obtenido al final del proceso.

\section{Aislamiento e identificación de cepas bacterianas}

Las pruebas preliminares para las cepas axénicas aisladas de los síntomas de tomate y ejote mostraron en placas con B de King, colonias redondas color crema, bordes redondos, elevadas, cremosas y brillantes, con la característica fluorescencia bajo la luz ultravioleta mostrada por las colonias de Pseudomona syringae del grupo fluorescente. La morfología microscópica muestra bacilos rojos, para la tinción gram es negativa, oxidasa negativa, catalasa positiva y ryu positivo. La identidad molecular de las bacterias fue corroborada por la secuenciación del material genético y en el National Center for Biotechnology Information (NCBI Blast) con el número de acceso JX876900.1 para Pseudomonas syringae pv. phaseolicola y AE016853.1 Pseudomonas syringae pv. tomato. 


\section{Actividad antimicrobiana de los extractos vegetales}

El efecto de la actividad bactericida de los diferentes extractos sobre el crecimiento de $P$. syringae ambos patovares (pv. phaseolicola y pv. tomato) determinado cada 24 h por siete días, mostró (Cuadro 1), la presencia de sustancias activas en los discos impregnados por los extractos principalmente etanolicos y metanolicos.

Cuadro 1. Efecto antibacteriano de extractos vegetales sobre Pseudomona syringae ambos patovares (pv. phaseolicola y pv. tomato) aislada de la sintomatología de peca bacteriana en tomate (Solanum lycopersicum) y mancha grasienta en ejote (Phaseolus vulgaris).
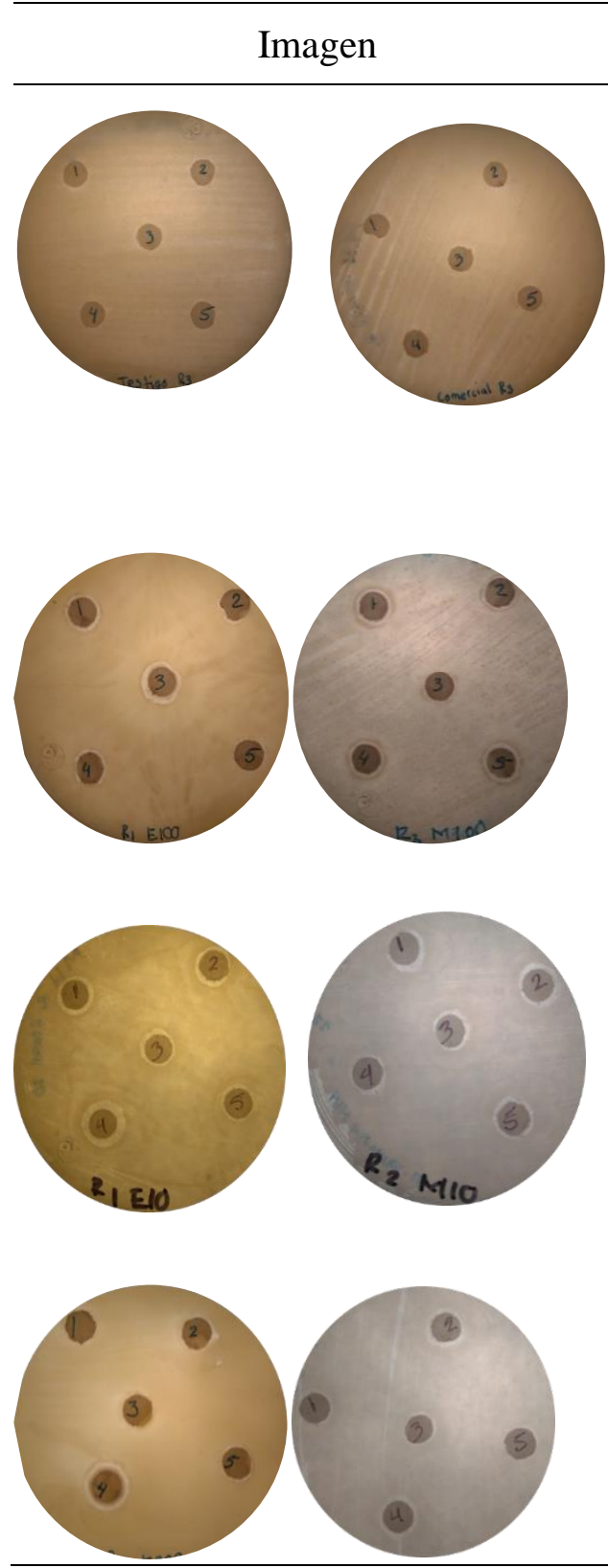

Concentración

Testigo absoluto y Controles absoluto y comercial testigo comercial $5 \mu \mathrm{ml}^{-1}$

Extractos base etanol y metanol crudo $100 \mathrm{mg} \mathrm{ml}^{-1}$ $300 \mathrm{mg} \mathrm{ml}^{-1}$ $500 \mathrm{mg} \mathrm{ml}^{-1}$

Extractos base Etanol y metanol $10 \mathrm{mg} \mathrm{ml}^{-1}$ $30 \mathrm{mg} \mathrm{ml}^{-1}$ $50 \mathrm{mg} \mathrm{ml}^{-1}$ $80 \mathrm{mg} \mathrm{ml}^{-1}$

Extractos base Etanol y metanol crudo $100 \mathrm{mg} \mathrm{ml}^{-1}$ $300 \mathrm{mg} \mathrm{ml}^{-1}$ $500 \mathrm{mg} \mathrm{ml}^{-1}$
No se observó presencia de halos de inhibición de Pseudomona syringae ambos patovares (pv. phaseolicola y pv. tomato) en el testigo absoluto y casi imperceptible (1 mm o menos) en el uso del producto comercial Gamma de Progranic.

Primer ensayo M. pomifera Los extractos de etanol y metanol presentaron actividad inhibitoria bacteriana. Donde etanol de 100 $\mathrm{mg} / \mathrm{ml}$ fue el tratamiento superior con una media de 0.8219 .

Segundo ensayo M. pomifera Los extractos de etanol y metanol presentaron actividad inhibitoria bacteriana. Donde el tratamiento más efectivo fue etanol de $10 \mathrm{mg} \mathrm{ml} \mathrm{en} \mathrm{la}$ inhibición de $P$. syringae Con una media de 0.9838 .

\section{Ensayo Z. officinale}

El tratamiento más sobresaliente fue de etanol de $100 \mathrm{mg} \mathrm{ml}$. Los extractos de base metanol $100 \mathrm{mg} \mathrm{ml}$ presentaron de igual forma actividad inhibitoria bacteriana en menor grado, con una media de 0.4166 . 
Las comparaciones de medias de los solventes utilizados como base de extracción en la que se prepararon los extractos se presentan en el Cuadro 2a, mientras que el Cuadro 2b, muestra la comparación de medias entre las concentraciones empleadas $\left(500,300,100 \mathrm{mg} \mathrm{ml}^{-1}\right)$. Destacando como mejor base de extracción al etanol y $100 \mathrm{mg} \mathrm{ml}$ a la concentración más efectiva al presentar la media más alta ante el efecto inhibitorio producido del extracto sobre $P$. syringae con una media de 0.8219 .

Cuadro 2a. Primer ensayo $M$. pomifera, concentraciones altas de extractos acuosos y alcohólicos. Comparación de medias entre los factores de análisis solventes de extracción y concentraciones. Comparación de medias entre las bases de extracción de acuerdo halo inhibitorio dado en $\mathrm{cm}(\mathrm{a})$.

\begin{tabular}{cccc}
\hline Base de extracción & Media & Sd & G \\
\hline Etanol & 0.702 & 0.363 & $\mathrm{a}$ \\
Metanol & 0.6207 & 0.321 & $\mathrm{~b}$ \\
Agua & 0.5760 & 0.291 & $\mathrm{c}$ \\
\hline
\end{tabular}

Cuadro 2b. Comparación de medias entre las concentraciones empleadas en presencia y tamaño del halo inhibitorio en cm (b). Con 210 evaluaciones, tres tratamientos de extractos crudos, tres solventes de extracción (etanol, metano y agua), cada uno con tres concentraciones respectivas $(100,300$ y $500 \mathrm{mg} \mathrm{ml})$, cada tratamiento con tres repeticiones (unidad de caja Petri) y cada repetición con cinco discos de papel dentro, impregnado con el tratamiento, determinando así cinco unidades de medida dentro de cada repetición, para todos los casos.

\begin{tabular}{cccc}
\hline Base de extracción & Media & Sd & G \\
\hline 100 & 0.8219 & 0.8219 & $\mathrm{~A}$ \\
300 & 0.7952 & 0.121 & $\mathrm{~B}$ \\
500 & 0.772 & 0.0898 & $\mathrm{C}$ \\
Crudo & 0.7755 & 0.1025 & $\mathrm{C}$ \\
Testigo & 0 & 0 & $\mathrm{D}$ \\
\hline
\end{tabular}

$\mathrm{Sd}=$ desviación estándar; $\mathrm{G}=$ agrupación.

En este análisis se encontraron diferencias significativas en los factores de base de extracción donde el etanol fue el tratamiento superior, y en el segundo factor, concentración, el tratamiento de 100 $\mathrm{mg} \mathrm{ml}$ fue el que presento mayores diámetros en los halos de inhibición registrados con una media de 0.8219 , siendo la concentración mínima probada, la más efectiva para el control de $P$. syringae. Lo que nos indica que no en todos los casos las concentraciones altas son las mejores en el control esperado, como se piensa en la mayoría de los casos. Apoyando esto, estudios que utilizaron extractos de Ka'a He'ẽ (Stevia rebaudiana (Bertoni) Bertoni) para en el control de la Septoriosis y mancha bacteriana del tomate (Solanum lycopersicum L.), mostraron en su dosis más baja de 50 $\mathrm{ml} \mathrm{L}^{-1}$ reduce la severidad de la Septoriosis en tomate, además de aumentar el área foliar, altura, longitud radicular y masa seca. Así como su dosis media de $150 \mathrm{ml} \mathrm{L}^{-1}$ redujo la severidad de la mancha bacteriana (Lesme et al., 2017). 
De manera opuesta, otras investigaciones con extractos de gobernadora, se observó que a mayor concentración se registró mayor inhibición, ya que las concentraciones de 0.7 y 0.35 ppm inhibieron totalmente el crecimiento de las cuatro bacterias (Pectobacterium carotovora subsp. carotovora, Xanthomonas axonopodis pv.phaseoli, Xanthomonas axonopodis pv. vesicatoria y Pseudomonas cichorii), mientras con el testigo no hubo inhibición del crecimiento (Osorio et al., 2009).

El efecto de ambos factores $\left(F_{8}, 1560\right), p<0.001$, también es significativo, esto se representa gráficamente de la Figura 1. Donde el tratamiento con los extractos a base de etanol, mostraron un comportamiento superior. Ramírez et al. (2015) estudiaron extractos etanolicos crudos con diferentes tejidos de Magnolia schiedeana sobre las bacterias fitopatógenas Pectobacterium carotovorum y Pseudomonas cichorii. Sus resultados indican que el extracto etanólico floral, al igual que en nuestro estudio, inhibió el crecimiento $P$. carotovorum en la misma proporción que el antibiótico probado $(p=0.079)$.

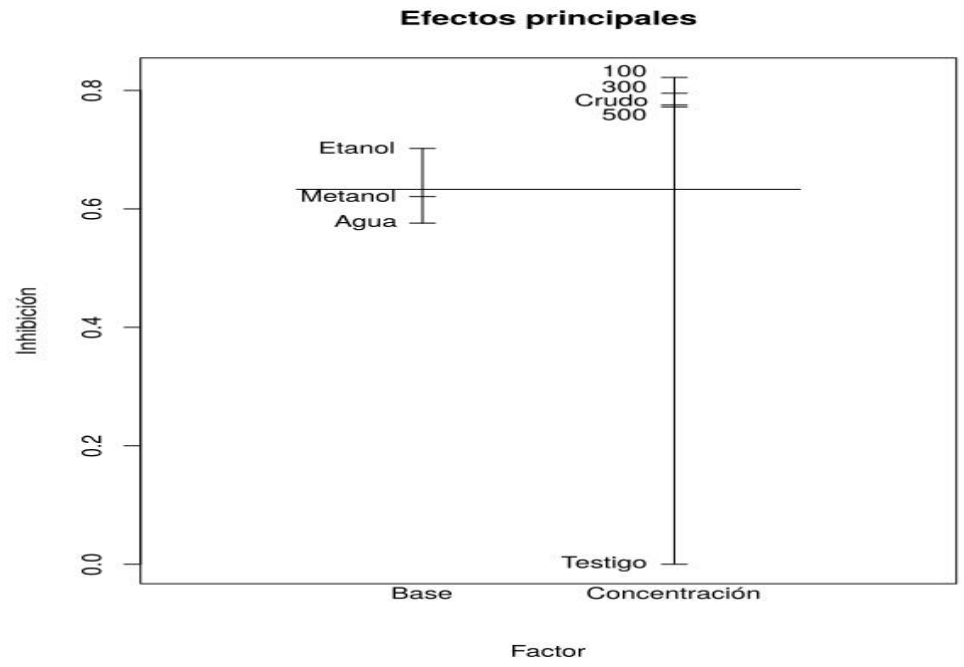

Figura 1. Comparación de los efectos principales de base de extracción y concentraciones de los tratamientos de Maclura pomifera contra $P$. syringae.

Los efectos principales representados en la Figura 1, esquematizan la separación de los factores. Sobresalen los extractos, sobre el testigo absoluto, siendo superiores los tratamientos de base etanol y la concentración $100 \mathrm{mg} \mathrm{ml}^{-1}$, presentando el mejor comportamiento en la inhibición del crecimiento bacteriano. En forma opuesta extractos de base agua y las concentraciones de $500 \mathrm{mg}$ $\mathrm{ml}^{-1}$ fueron los tratamientos donde la respuesta inhibitoria fue menor, aunque se encuentre por encima del testigo absoluto.

El factor de concentraciones está representado gráficamente en la Figura 2, donde se observa la inhibición más alta en las concentraciones de $300 \mathrm{y} 100 \mathrm{mg} \mathrm{ml}^{-1}$, marcando un ahusado pico en los extractos elaborados en base de etanol en todos los casos estudiados. Por lo que, de igual manera se reitera que las concentraciones bajas producen un mayor efecto inhibitorio. Y por lo cual, basado en los resultados analizados, se diseñó un segundo ensayo con concentraciones mínimas para evaluar un mejor comportamiento y control producido por los extractos vegetales y sus componentes disueltos. 


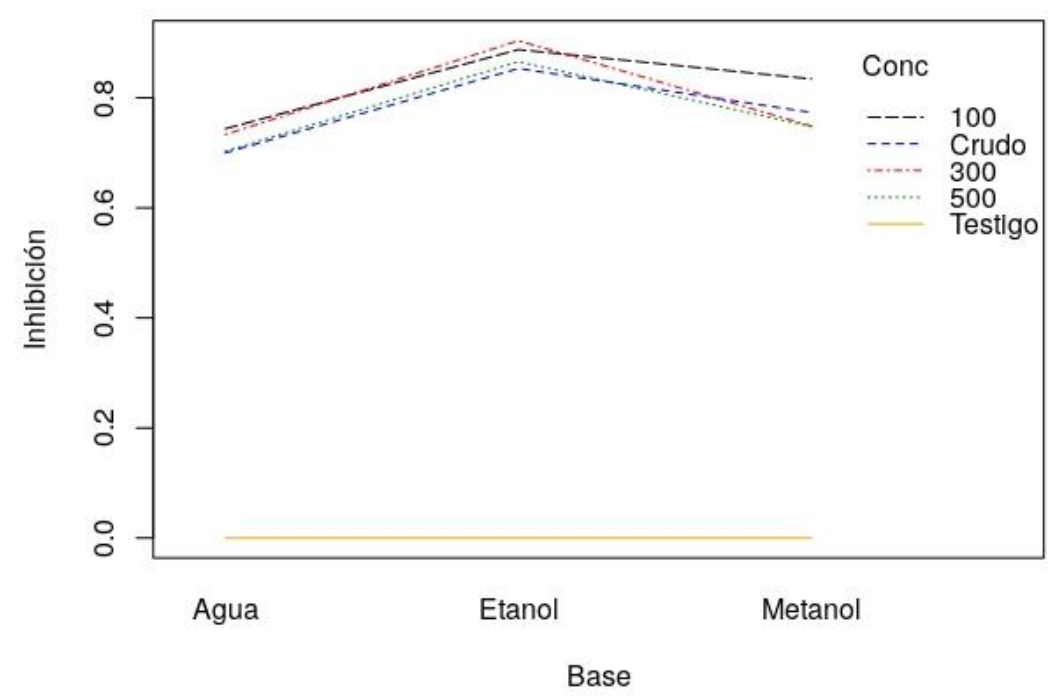

Figura 2. Comparación del efecto inhibitorio de concentraciones en los tratamientos de Maclura pomifera en tres bases de extracción, contra $P$. syringae.

La disolución de los compuestos activos en los extractos vegetales depende de la base de extracción utilizada, en la cual se encuentran disueltos compuestos, dependiendo de su afinidad con el solvente, por lo cual, la naturaleza de esta base de extracción puede aumentar o disminuir los efectos del extracto dependiendo los componentes disueltos en ella o su dispersión sobre la superficie aplicada. La presencia de metabolitos secundarios en los extractos vegetales es una característica que forman parte de las estrategias defensivas de las plantas (Celis et al., 2009).

Dadas estas condiciones, los solventes alcohólicos para esta investigación presentaron el mejor comportamiento ante la inhibición bacteriana, posiblemente por la naturaleza de los metabolitos de la planta presentes. A diferencia de otras especies como Citrus x paradisi, Pimienta dioica, Origanummajorana, Tilia platyphyllos, las cuales en extractos acuosos a la concentración de 25\%, presentaron inhibición en el crecimiento micelial de 100\% sobre el hongo Moniliophthora roreri, aislado de frutos enfermos de cacao, a diferencia del testigo que presentó un radio de crecimiento de $25 \mathrm{~mm}$ (Arcos et al., 2019).

Los datos para el segundo ensayo de $M$. pomifera se analizaron en un método factorial, donde nuevamente los factores de concentración y base de extracción mostraron, diferencias significativas en el Cuadro 3, para el caso de la base de los extractos, $\left(F_{1,832}\right)=116.8, p<0.001$, mientras que la diferencia entre concentraciones es de $\left(F_{3,832}\right)=40.492, p<0.001$.

Basados en los resultados del primer ensayo se eligió a los extractos etanolicos y metanolicos, como los mejores tratamientos en la inhibición bacteriana de $P$. syringae. De igual forma, tomando en cuenta que la concentración menor $\left(100 \mathrm{mg} \mathrm{ml}^{-1}\right)$ del ensayo anterior fue la más efectiva con media de 0.8219 , se seleccionaron concentraciones por debajo de este valor para establecer el nuevo diseño. El efecto inhibitorio antibacteriano se presentó en todos los casos con extractos de etanol y metanol. 
Cuadro 3. Segundo ensayo $M$. pomifera, disminución de concentraciones de extractos Etanolico y Metanolico y su efecto inhibitorio sobre P. syringae. Comparación de medias entre los factores de análisis bases de extracción y concentraciones. Comparación de medias de la base de extracción etanol y metanol (a), comparación de medias entre las concentraciones empleadas de cada tratamiento $10,30,50$ y $80 \mathrm{mg} \mathrm{ml}^{-1}$ (b), con 210 evaluaciones totales, cotejando el tamaño en $\mathrm{cm}$ de los halos inhibitorios producidos.

a)

\begin{tabular}{cccc}
\hline Base de extracción & Media & Sd & G \\
\hline Etanol & 0.9616 & 0.1729 & $\mathrm{a}$ \\
Metanol & 0.868 & 0.0807 & $\mathrm{~b}$ \\
\hline
\end{tabular}

b)

\begin{tabular}{cccc}
\hline Base de extracción & Media & $\mathrm{Sd}$ & $\mathrm{G}$ \\
\hline 10 & 0.9838 & 0.1729 & $\mathrm{a}$ \\
30 & 0.8938 & 0.0807 & $\mathrm{~b}$ \\
50 & 0.9280 & 0.1622 & $\mathrm{c}$ \\
80 & 0.8538 & 0.1012 & $\mathrm{~d}$ \\
\hline
\end{tabular}

El Cuadro 4a muestra la diferencia entre las medias de los tratamientos, ubicando al tratamiento de etanol con un efecto bactericida superior, mientras que el Cuadro $4 \mathrm{~b}$ señala la concentración de 10 $\mathrm{mg} \mathrm{ml}$ como el tratamiento más efectivo para el control del patógeno $P$. syringae.

La inhibición del crecimiento bacteriano por extractos vegetales ha sido documentada por investigadores en los últimos años, buscando el sustento científico de los componentes activos en los extractos, que son de menor costo y con efectividad amplia. Como lo demuestran estudios de extractos de semillas de Citrus paradisi (toronja) inhibiendo patógenos bacterianos como Escherichia coli, Staphylococcus aureus, Pseudomonas aeruginosa y el hongo Candida albicans (Cabrera, 2019).

Cuadro 4. Primer ensayo $Z$. officinale, concentraciones altas de extractos acuosos y alcohólicos. Comparación de medias entre dos factores, las bases de extracción (a). Comparación de medias entre las concentraciones empleadas (b). Con 210 evaluaciones totales, tres tratamientos de extractos crudos, tres solventes de extracción (etanol, metano y agua), cada uno con tres concentraciones respectivas $\left(100,300\right.$ y $\left.500 \mathrm{mg} \mathrm{ml}^{-1}\right)$, cada tratamiento con tres repeticiones (unidad de caja Petri) y cada repetición con cinco discos de papel dentro, impregnado con el tratamiento, determinando así cinco unidades de medida dentro de cada repetición, para todos los casos, evaluando el tamaño en $\mathrm{cm}$ de los halos inhibitorios producidos.

a)

\begin{tabular}{cccc}
\hline Base de extracción & Media & Sd & $\mathrm{G}$ \\
\hline Etanol & 0.1951 & 0.3369 & $\mathrm{a}$ \\
Metanol & 0.1081 & 0.2679 & $\mathrm{~b}$ \\
Agua & 0 & 0 & $\mathrm{c}$ \\
\hline
\end{tabular}


b)

\begin{tabular}{cccc}
\hline Base de extracción & Media & $\mathrm{Sd}$ & $\mathrm{G}$ \\
\hline 100 & 0.4166 & 0.3833 & $\mathrm{a}$ \\
300 & 0.0888 & 0.2518 & $\mathrm{~b}$ \\
500 & 0 & 0 & $\mathrm{c}$ \\
Crudo & 0 & 0 & $\mathrm{c}$ \\
Testigo & 0 & 0 & $\mathrm{c}$ \\
\hline
\end{tabular}

$\mathrm{Sd}=$ desviación estándar; $\mathrm{G}=$ agrupación.

Al igual que el efecto entre base y concentraciones es significativo $\left.F_{3,832}\right)=8.612, p<0.001$, se presenta la figura de efectos principales (Figura 3 ), donde se refleja la eficacia de los tratamientos de etanol de $10 \mathrm{mg} \mathrm{ml}^{-1}$.

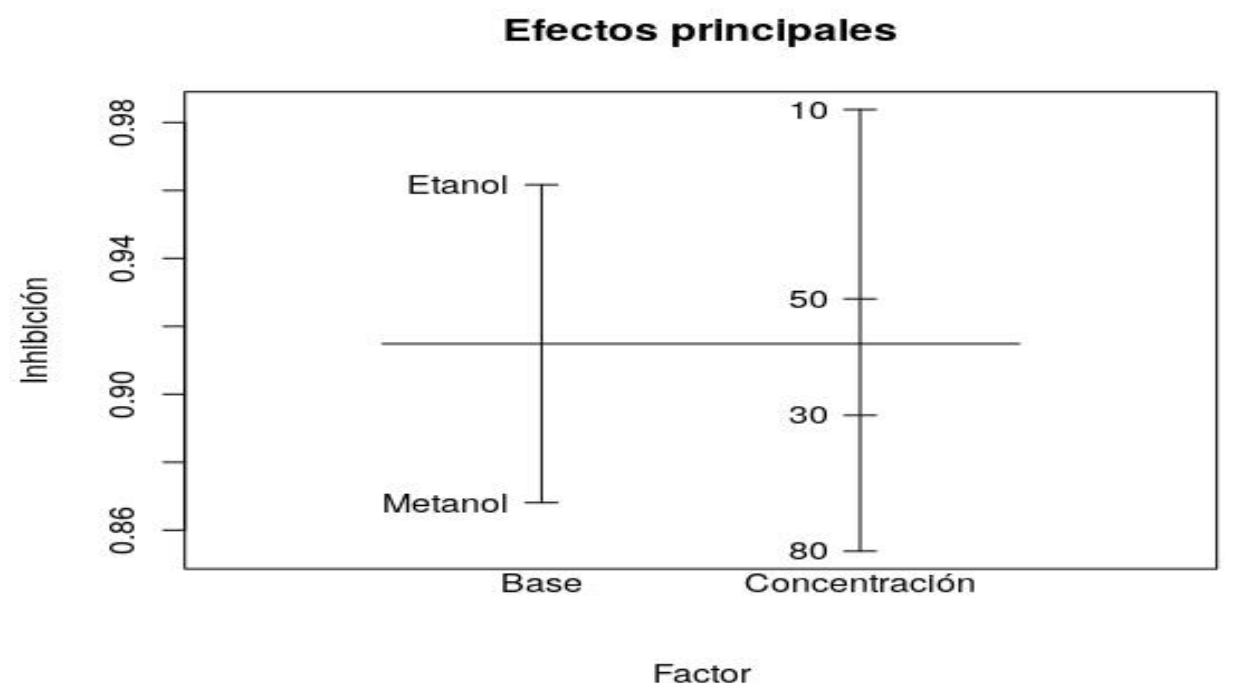

Figura 3. Segundo ensayo, disminución de concentraciones, extracto de M. pomifera. Efectos principales de inhibición bacteriana de bases de extracción y concentraciones sobre $P$. syringae.

El comportamiento de los extractos en el segundo ensayo de M. Pomifera representado en la Figura 4, reitera, a los extractos de base etanol con un efecto superior en la inhibición de P. syringae y al segundo factor, concentración, de igual manera sobresaliendo el tratamiento de menor concentración $\left(10 \mathrm{mg} \mathrm{ml}^{-1}\right)$ como el más efectivo en esta misma evaluación.

El comparativo de extracto vegetal contra producto comercial se analizó por medio de estadística no paramétrica. El producto comercial fue comparado con la mejor concentración $\left(10 \mathrm{mg} \mathrm{ml}^{-1}\right)$, con base de etanol, siendo esta la media de inhibición más alta. Los datos se analizaron mediante la prueba de suma de rangos de Wilcoxon (Wilcoxon rank sum test: $\mathrm{W}=11025$, $\mathrm{p}$-value $<2.2$ e-16), las medianas son estadísticamente diferentes. 


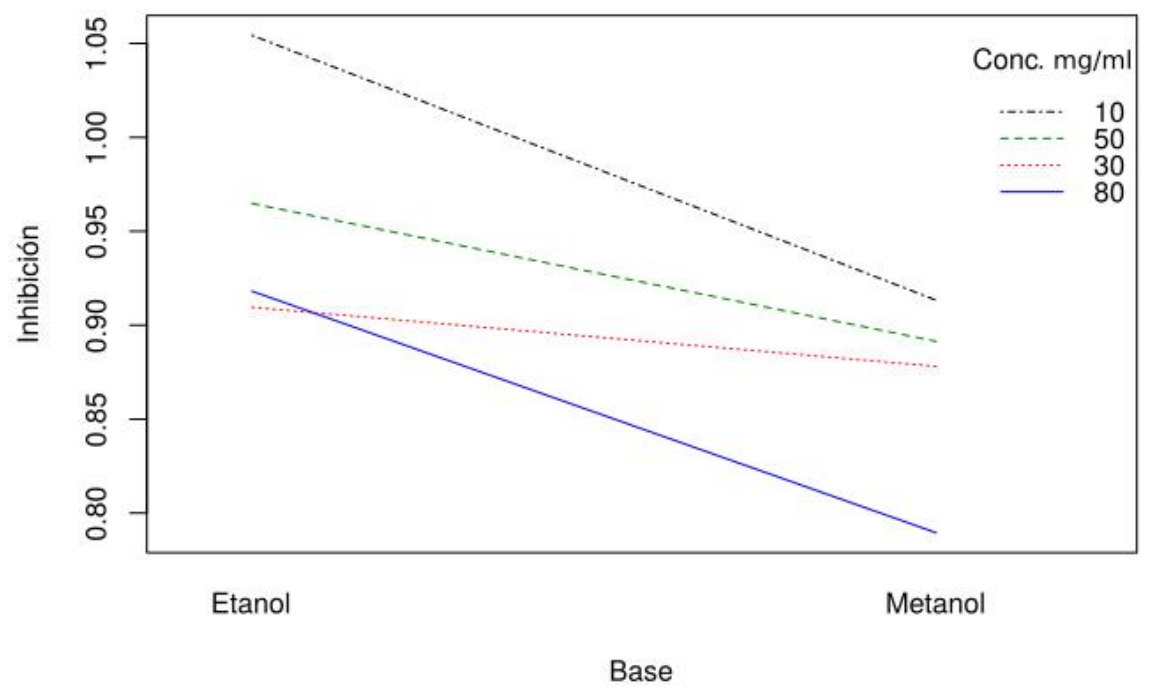

Figura 4. Segundo ensayo, disminución de concentraciones extracto de $M$. pomifera. Interacción factor de inhibición bacteriana de base de extracción y concentración, sobre $P$. syringae.

En la Figura 5 se observa, la superioridad de efecto antimicrobiano del extracto de etanol $10 \mathrm{mg}$ $\mathrm{ml}^{-1}$, sobre la inhibición del producto comercial Gamma de Progranic (extracto de ajo (Allium sativum 25\%), extracto de chile picante (Capsicum frutescens 25\%), extracto de canela (Cinnamomum zeylanicum 10\%) de 1.5-2 $\mathrm{L} \mathrm{ha}^{-1}$ en $200 \mathrm{~L}$ de agua).

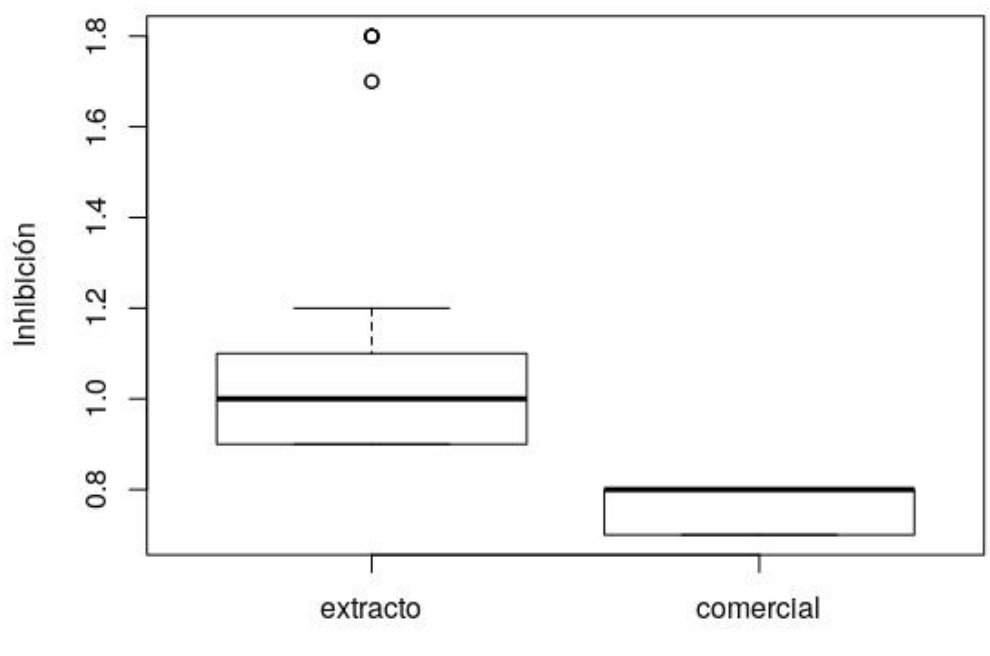

Producto

Figura 5. Segundo ensayo, disminución de concentraciones extracto de $M$. pomifera. Comparativo de extractos vegetales contra producto comercial evaluando el efecto de inhibición bacteriana, sobre $P$. syringae.

Para el ensayo con los extractos de Z. officinale, los datos registrados en el Cuadro 4, se analizaron bajo un diseño factorial y agrupación de medias, con 14 tratamientos, tres repeticiones por cada tratamiento, y cada unidad experimental con cinco elementos de medida, que fueron el número de discos por caja. 
El Anova demostró diferencias significativas entre los tratamientos y los datos fueron analizados en un arreglo factorial, del cual, se separaron dos factores principales, como base de extracción y concentración, tal como se muestran en el Cuadro 4a y 4b respectivamente. Destacando como grupos principales con el mayor efecto inhibitorio la base de extracción etanol y la concentración de $100 \mathrm{mg} \mathrm{ml}^{-1}$ correspondientes a cada uno de los factores analizados mostrados en la Figura 6.

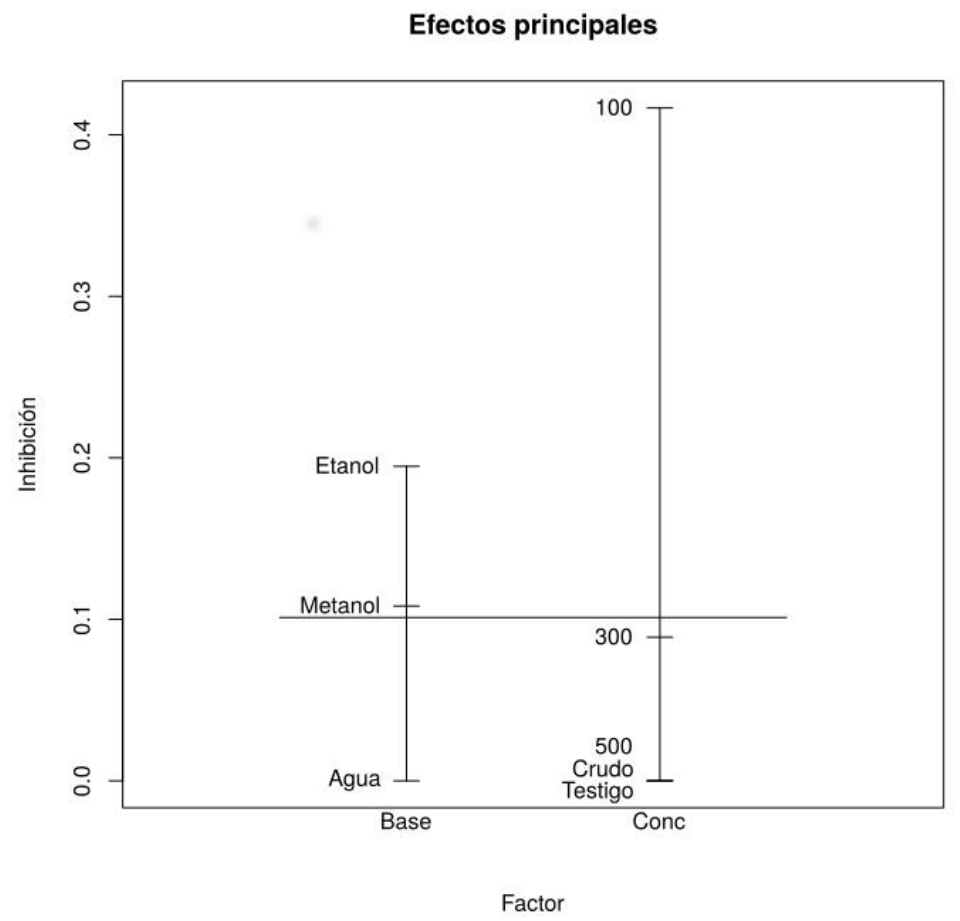

Figura 6. Efectos principales de la inhibición bacteriana de Base de extracción y concentración de extractos de $Z$. officinale sobre $P$. syringae.

Los efectos principales se separaron en dos grupos, base de extracción y concentración. Como se demuestra en la Figura 6, en el primer grupo de bases de extracción, los extractos de base etanolica mostraron un efecto superior en la inhibición de $P$. syringae. Mientras que para el efecto de concentración mostro una amplia separación del grupo la concentración de $100 \mathrm{mg} \mathrm{ml}^{-1}$, al registrar los halos inhibitorios mayores.

La Figura 7 muestra el comportamiento, como en función al tipo de base, a medida que disminuye la concentración del extracto, aumenta el efecto inhibitorio sobre la bacteria. Presentando picos marcados en la base etanol y el aumento inhibitorio en la concentración de $100 \mathrm{mg} \mathrm{ml}^{-1}$.

Actualmente, así como esta investigación, existen fuentes y estudios acerca de los componentes activos de las plantas con diversos usos terapéuticos, insecticidas fungicidas y bactericidas. $Z$. officinale demostró efectos bactericidas en extractos a base de etanol, como una alternativa en el biocontrol. En Argentina estudios de extractos hidroalcohólicos (etanol: agua, 1:1) de 80 especies silvestres de diversas regiones del país, mostraron inhibición frente a Staphylococcus aureus en $41.25 \%$ de las especies estudiadas. Demostrando así el valor de los extractos vegetales en el control bilógico (Toribio et al., 2009). 


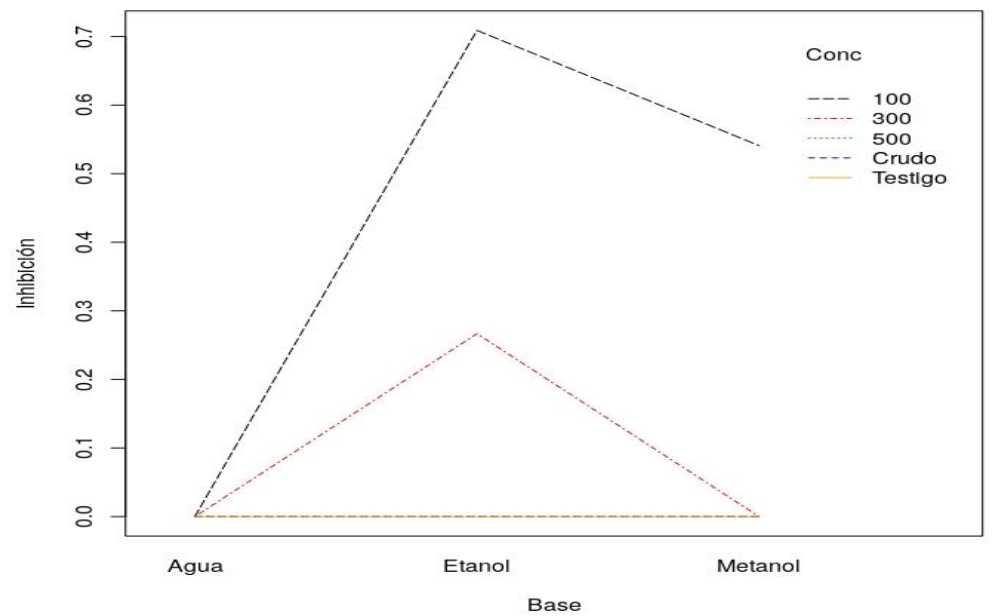

Figura 7. Efecto inhibitorio de crecimiento bacteriano, producido por los extractos de Z. officinale sobre $P$. syringae. En función de la base de extracción y su concentración.

Recientemente Celaya et al. (2019) corrobora la eficiencia de extractos hidroetanolicos mostraron en su investigación que el extracto de Eucalyptus globulus y la mezcla de 12 extractos presentaron actividad antimicrobiana contra Escherichia coli, Listeria monocytogenes, Salmonella typhimurium, Vibrio cholerae y Staphylococcus aureus $(p<0.05)$.

\section{Conclusiones}

Los extractos de etanol y metanol presentaron inhibición del crecimiento y desarrollo de Pseudomona syringae de tomate y ejote bajo condiciones in vitro. Particularmente los extractos de $M$. pomifera en su primer y segundo ensayo mostraron el máximo efecto inhibitorio en los tratamientos etanolicos con las menores concentraciones, que en el caso del primer ensayo fue de $100 \mathrm{mg} \mathrm{ml} \mathrm{y} \mathrm{para} \mathrm{el} \mathrm{segundo} \mathrm{ensayo} \mathrm{en} \mathrm{la} \mathrm{disminución} \mathrm{de} \mathrm{concentraciones} \mathrm{la} \mathrm{mejor} \mathrm{concentración}$ fue de $10 \mathrm{mg} \mathrm{ml}^{-1}$, sobre $P$. syringae pv tomato.

El mayor efecto inhibitorio de $P$. syringae pv phaseolicola con extractos de Z. officinale fue registrado por los extractos con base etanolica y en la concentración de $100 \mathrm{mg} \mathrm{ml}^{-1}$. Los resultados obtenidos dan pauta a estos extractos para ser considerados en un programa de control biológico, en si siguiente etapa in vivo, siendo una alternativa de biocontrol para enfermedades bacterianas, efectiva, de bajo costo y menor o nulo impacto ambiental.

\section{Literatura citada}

Abadie, R.; Medina, R.; Ruiz, L. y Tresierra, A. 2014. Actividad antibacteriana de extractos vegetales frente a cepas intrahospitalarias, Iquitos-Perú. Rev. ECIPerú. 11(1):31-38.

Agrios, G. N. 2005. Plant pathology. $5^{\text {th }}$ English edition. (Ed.). Elsevier Academic Press. $5^{\text {th }}$ Ed. United States of America. 624-634 pp.

Arcos, M. C.; Martínez, L.; Ortiz, G.; Martínez, M. y Avendaño, C. H. 2019. Efecto in vitro de extractos vegetales contra la Moniliasis (Moniliophthora Roreri) del cacao (Theobroma Cacao L.). Rev. Agric. Tropical. 5(1):19-24. 
Cabrera, C. E. 2019. Actividad antimicrobiana de un sistema a base de un extracto vegetal y tres aceites esenciales. Ciencia e Investigación. 22(1):21-26.

Celaya, H.; Anaya, J.; Barrera, M. A.; Barrales, S. M.; Nieblas, M.; Osuna, R. F.; Ibarra, C.; López, G.; Heredia, P. y Sosa, J. 2019. Extractos hidro-etanólicos de plantas comestibles como alternativa para controlar bacterias patógenas, parásitos e insectos en la industria pecuaria. Biotecnia. 2(21):47-54 https://doi.org/10.18633/biotecnia.v21i2.905.

Celis, A.; Mendoza, F. y Pachón, M. E. 2009. Uso de extractos vegetales en el manejo integrado de plagas, enfermedades y arvenses. In: Temas agrarios: 14(1):5-16. https://doi.org/10.21897/rta.v14i1.1205.

Cúndom, M.; Agueda, N. Y. y Gutiérrez, S. A. 2016. Ramulispora sorghi patógeno en cultivos de sorgo del NE de Argentina. Summa Phytopathologica. 42(2):183-184. https://doi.org/10.1590/0100-5405/2113.

FAO. 2017. Food and Agriculture Organization of the United Nations. Resistencia a los antimicrobianos: lo que necesitas saber. [on line]. http://www.fao.org/zhc/detailevents/es/c/452719/.

Lépiz, R. S; Sánchez, E.; López, J. J.; López, I. E.; Chavarín, E. y Meza, K. E. 2015. El cultivo del frijol en Jalisco. Tecnología para altos rendimientos. $1^{\mathrm{a}}$ Ed. Prometeo editores. Guadalajara, Jalisco, México. i. e. 54 p. ISBN: 978-607-8336-60-9.

Lépiz, R.; López, J. J.; González, C. y Rodríguez, E. 2016. Cuarenteño, nueva variedad de frijol de tipo cacahuate para el estado de Jalisco, México. Rev. Fitotec. Mex. 39(4):415-416. https://www.redalyc.org/articulo.oa?id=610/61049142011.

Lesme, J. A.; Soilán, L. C. y Grabowski, C. J. 2017. Extracto de Ka’a He' ẽ [Stevia rebaudiana (Bertoni) Bertoni] en el control de la Septoriosis y mancha bacteriana del tomate (Solanum lycopersicum L.). Investigación Agraria. 19(2):101-111.

Osorio, E.; Ventura, J. M.; Flores, M.; Lara, F.; Rodríguez, R.; Hernández, F. D. y Aguilar, C. N. 2009. Efectividad biológica de extractos polifenólicos contra bacterias fitopatógenas. Rev. Digital de Divulgación Científica. 1(2):1-6. http://www.posgradoeinvestigacion.uadec.mx /AQM/No.\%202/AQM2efectividadbiologica.html.Producción_frijol_noviembre_2019.pdf.

Pérez, A.; Hermosa, R. y Monte, E. 2017. Actividades de biocontrol de Trichoderma frente a ascomicetos fitopatógenos. Farma J. 2(1):85-93. URI: http://hdl.handle.net/10366/133695.

Pérez, E.; Bernal, A.; Milanés, P.; Sierra, Y.; Leiva, M.; Marín, S. y Monteagudo, O. 2018. Eficiencia de Trichoderma harzianum (cepa A-34) y sus filtrados en el control de tres enfermedades Fúngicas foliares en arroz. Bioagro. 30(1):17-26.

Ramírez, T.; Flores, N.; Luna, M.; Noa, J. C.; Sánchez, L. R. y Trigos A. 2015. Extractos crudos de Magnolia Schiedeana schltdl. para el control de bacterias ftopatógenas. Madera y Bosques. 2 (21):159-164.

R-Core, Team. 2020. R: a language and environment for statistical computing. R Foundation for Statistical Computing, Vietnam, Austria. URL https://www.R-project.org/.

Reyes, M.; Rincón, G.; López, L.; Evangelista, Z. y Quiñones, E. 2015. Lucha entre microbios: una herramienta para el control de enfermedades de plantas. Rev. Digital Universitaria. 1(16):15-21. De http://www.revista.unam.mx/vol.16/num11/art92/ Base de datos.

Ríos, E. N.; Partida, L. P.; Ochoa, Y. M.; Cerna, E.; Hernández, F. D.; Flores, A.; Olalde, V. y Rodríguez, R. 2016. First report on the presence of Phyllachora sp. in corn crops at Toluca, Estado de Mexico. Am. J. Plant Sci. 7(5):733-739. De scientific research an academic publisher bases de datos. DOI: 10.4236/ajps.2016.75067. 
Rojas, J.; Velasco, J.; Buitrago, A.; Mender, T. y Rojas J. 2016. Evaluación de la actividad antimicrobiana de plantas medicinales seleccionadas del Jardín Botánico del Orinoco, municipio Heres, Estado Bolívar. Rev. Facultad de Odontología. 58(1):2-10. De Researchgate.net Base de datos.

SIAP. 2019. Servicio de Información Agroalimentaria y Pesquera. https://www.gob.mx/cms/uploads/attachment/file/517489/Boletin_mensual_de_la_.

SIAP. 2019. Servicio de Información Agroalimentaria y Pesquera. https://www.gob.mx/cms/uploads/attachment/file/518034/Bolet_n_avance_produccion_ tomate_rojo_noviembre_2019.pdf .

Solís-Aguilar, A. J. y Armas-Soto, M. C. 2017. Alternativas biológicas para el manejo del complejo de manchado de grano en el cultivo de arroz en Babahoyo, provincia de Los Ríos, Ecuador. Rev. Cient. Cien. Nat. Ambien. 11(1):37-48.

Toribio, M. S.; Oriani, S. D.; Toso, R. E.; Tortone, C. A. y Fernández, J. G. 2009. Staphylococcus aureus sensible a extractos metanólicos obtenidos de plantas nativas de la provincia de la pampa, argentina. Rev. Veterinaria. 1(11):14-18.

Zhang, S.; Fu, Y.; Mersha, Z. and Pernezny, K. 2017. Assessment of copper resistance in Pseudomonas syringae pv phaseolicola, the pathogen of halo blight on snap bean. Crop Protec. 1(98):8-15. http://dx.doi.org/10.1016/j.cropro.2017.03.009. 